\title{
Effect of low dose aspirin and dipyridamole on primary patency of arteriovenous grafts in hemodialysis patients: a randomized double-blind placebo-controlled trial
}

\author{
Pouya Tayebi ${ }^{1}$, Gholamhosein Kazemzadeh ${ }^{2}$, Azin Banihashem ${ }^{3}$, Hassan Ravari $^{4}$
}

\begin{abstract}
${ }^{1}$ M.D., Fellowship of Vascular Surgery, Vascular and Endovascular Surgery Research Center, Imam Reza Hospital, Faculty of Medicine, Mashhad University of Medical Sciences, Mashhad, Iran

${ }^{2}$ M.D., Associate Professor of Vascular Surgery, Vascular and Endovascular Surgery Research Center, Imam Reza Hospital, Faculty of Medicine, Mashhad University of Medical Sciences, Mashhad, Iran

${ }^{3}$ M.D., General Surgeon, Vascular and Endovascular Surgery Research Center, Department of Vascular Surgery, Imam Reza Hospital, Faculty of Medicine, Mashhad University Of Medical Sciences, Mashhad, Iran

${ }^{4}$ M.D., Professor of Vascular Surgery, Vascular and Endovascular Surgery Research Center, Imam Reza Hospital, Faculty of Medicine, Mashhad University of Medical Sciences, Mashhad, Iran
\end{abstract}

\section{Type of article: Original}

\begin{abstract}
Background: There is some evidence for the efficacy of antiplatelet therapies in increasing the vascular access patency duration or decreasing the thrombosis of arteriovenous grafts.

Objective: To determine the effect of low dose aspirin and dipyridamole on primary patency of arteriovenous grafts in hemodialysis patients

Methods: This randomized, double-blind, placebo-controlled trial was done at Imam Reza Hospital in Mashhad, Iran from September 10, 2015 to July 05, 2016. Sixty hemodialysis patients, after the placement of a new arteriovenous graft, were divided into three study groups which including; Group 1, who received $80 \mathrm{mg}$ aspirin tablet daily, Group 2 received $80 \mathrm{mg}$ aspirin plus $75 \mathrm{mg}$ dipyridamole daily and Group 3 received placebo daily. Primary unassisted patency was recorded in follow-up until 12 months and the outcomes were analysed using one-way ANOVA test.

Results: Primary patency time in Group 1 (Aspirin) was 324.75 \pm 147.00 day and for Group 2 (Aspirin + Dipyridamole) was $399.05 \pm 92.09$ day and for Group 3 (Placebo) was $383.55 \pm 108.23$ day. There were no significant differences between the 3 groups ( $>0.05$ ). Successful dialysis was done in $16.7 \%$ in Group 1, 37.5\% in Group 2 and $45 \%$ in Group 3 from brachial arteriovenous grafts after 1 -year follow-up ( $\mathrm{p}=0.746$ ).

Conclusions: In treating dialysis patients, treatment with low dose aspirin and dipyridamole is not effective on increasing the synthetic grafts primary patency duration.

Trial registration: The trial was registered at the Thai Clinical Trials Registry (http://www.clinicaltrials.in.th) with the Trct id: TCTR20160920003.

Funding: The authors received no financial support for the research, authorship, and/or publication of this article.

Keywords: Aspirin, Dipyridamole, Primary patency, Arteriovenous grafts
\end{abstract}

\section{Introduction}

Vascular access failure is known as a principal cause of morbidity of end stage renal disease (ESRD) patients. Hemodialysis vascular access can be provided by central venous catheter, autogenous fistula or arteriovenous graft $(1,2)$. Prosthetic vascular grafts are used in hemodialysis patients to connect an artery to a vein in order to pass the arterial blood flow which is necessary for effective dialysis. These kinds of vascular access are most common in the United States for patients who are not candidates for creating arteriovenous fistula in upper extremities (3).

\section{Corresponding author:}

Professor Hassan Ravari, Vascular and Endovascular Surgery Research Center, Imam Reza Hospital, Mashhad University of Medical Sciences, Mashhad, Iran.

Tel: +98.5118525311-8022505, Fax: +98.5118525311, Email: ravarih@mums.ac.ir

Received: July 08, 2016, Accepted: November 15, 2016, Published: January 2018

iThenticate screening: October 07, 2016, English editing: December 26, 2017, Quality control: January 12, 2018

(C) 2018 The Authors. This is an open access article under the terms of the Creative Commons Attribution-NonCommercialNoDerivs License, which permits use and distribution in any medium, provided the original work is properly cited, the use is non-commercial and no modifications or adaptations are made. 
However, the benefits of the grafts are that they are less likely to be dialyzed than fistulas over a period of time and they are more easily cannulated, but due to the higher likelihood of venous anastomosis stenosis, the chance for them to be thrombosed is greater (4), so there is a need to use a more expensive procedure to open and maintain them (5). The most common cause of grafts failure in dialysis patients is thrombosis due to the stenosis (1). The major reason for vascular access failure is the neointimal hyperplasia which leads to venous thrombosis and stenosis (6). The efficacy of different pharmacological therapies has been studied in increasing the vascular access patency duration or decreasing the thrombosis of arteriovenous grafts or fistulas. In 2015, a new edition of Cochrane Peripheral Vascular Diseases for cases of drug therapies in dialysis patients through arteriovenous fistula or prosthetic vascular graft was published. In this edition, the use of anti-platelet and anti-coagulant agent in comparison to placebo were discussed, and according to the result of a meta-analysis study, it is likely that the use of Ticlopidine (an anti-platelet treatment) in reducing the stenosis, and consequently a longer vascular access patency has beneficial effects. There is no definitive evidence for the positive effect of these drugs (such as aspirin, dipyridamole, dipyridamole plus aspirin, warfarin) on placebo in increasing the patency of grafts in dialysis patients (7). Therefore, we performed a randomized, double-blind, placebo-controlled trial to assess the primary unassisted patency of newly created arteriovenous grafts with the use of these anti-platelet drugs in ESRD patients.

\section{Material and Methods}

\subsection{Trial design and participants}

This randomized, double-blind, placebo-controlled trial was followed-up at the Imam Reza Hospital of Mashhad University of Medical Sciences between 2013 and 2014. Sixty ESRD patients who underwent placement of a new brachial arteriovenous graft have been included. The exclusion criteria were patients younger than 20 years old, pregnancy, and all comorbidities that the use of antiplatelet medication was contraindicated.

\subsection{Intervention}

They were divided randomly into three studied groups which included; Group 1, who received $80 \mathrm{mg}$ aspirin daily $(\mathrm{n}=20)$, Group 2, who received $80 \mathrm{mg}$ aspirin plus $75 \mathrm{mg}$ dipyridamole daily $(\mathrm{n}=20)$ and Group 3 , who received placebo daily $(\mathrm{n}=20)$. All synthetic grafts used Gore-Tex $6 \mathrm{~mm} \times 25 \mathrm{~cm}$ with end to side anastomosis in brachial artery and axillary vein anastomosis sites.

\subsection{Outcomes}

Patients were followed-up monthly after graft surgery to examine the access site; to record access-related complications. Loss of graft patency was defined by the absence of both a bruit and thrill. Primary unassisted patency time was recorded in follow-up every each month up to 12 months. Primary unassisted graft patency time is defined as the first occurrence of graft thrombosis, or other procedure performed to correct a stenosis of $50 \%$ or more of the diameter of the adjacent normal vessel, or other surgical modification of the graft (e.g., for infection) after graft surgery (8).

\subsection{Statistical methods}

Statistical analysis was conducted using SPSS17 software (SPSS, Inc., Chicago, IL, USA). Data from each patient were analyzed according to the patient's treatment group with the use of Kruskal-Wallis one-way analysis of variance test (ANOVA test). A p-value $<0.05$ was considered statistically significant.

\subsection{Research ethics}

The Ethic Committee of Mashhad University of Medical Sciences confirmed this study. Also the study was registered in the Thai Clinical Trials Registry (http://www.clinicaltrials.in.th) with the Trct id: TCTR20160920003. All patients were informed about this study and its complications, and each patient provided written informed consent before enrolment.

\section{Results}

In this study, 27 patients (45\%) were female and $33(55 \%)$ were male. The mean of patient's age was $55.69 \pm 13.9$ years old. There were no significant differences in patient's demographic characteristic between the three studied groups. The mean \pm SD of primary patency time in Group 1 (Aspirin) was $324.75 \pm 147.00$ per day and for Group 2 (Aspirin + Dipyridamole) was 399.05 \pm 92.09 per day and for Group 3 (Placebo) was $383.55 \pm 108.23$ per day. There were no significant differences between the 3 groups ( $>0.05)$. Primary unassisted patency time in each studied group is shown in Table 1. There were no significant differences in graft induced complications. Incidence of graft infection in Group 1 (Aspirin) was 5.6\% and in Group 2 (Aspirin + dipyridamole), was 5\% in the 1-year follow-up 
$(\mathrm{p}=0.460)$. Also, the incidence of bleeding after dialysis was $10 \%$ in Group 2 (Aspirin + dipyridamole) and there were no haemorrhagic events in Group 1 (Aspirin). The frequency of observed complication in patients' 1-year follow-up is seen in Table 2. After one-year follow-up, successful dialysis from brachial arteriovenous grafts was done in $16.7 \%$ in Group 1 (Aspirin), 37.5\% in Group 2 (Aspirin + Dipyridamole) and 45\% in Group 3 (Placebo) $(\mathrm{p}=0.746)$. Patient's survival rate was $83 \%$ in Group 1 (Aspirin), $83 \%$ in Group 2 (Aspirin + Dipyridamole) and $80 \%$ in Group 3 (Placebo) $(\mathrm{p}=0.813)$.

Table 1. Grafts' primary unassisted patency time frequency in each studied group.

\begin{tabular}{|l|l|l|l|}
\hline Primary patency time (days) & Group 1 (Aspirin) & Group 2 (Aspirin + Dipyridamole) & Group 3 (Placebo) \\
\hline$<90$ & $3(15 \%)$ & 0 & 0 \\
\hline $90-180$ & $2(10 \%)$ & $1(5 \%)$ & $3(15 \%)$ \\
\hline $180-270$ & $2(10 \%)$ & $1(5 \%)$ & 0 \\
\hline $270-360$ & $3(15 \%)$ & $1(5 \%)$ & 0 \\
\hline$>360$ & $10(50 \%)$ & $17(85 \%)$ & $17(85 \%)$ \\
\hline Total & $20(100 \%)$ & $20(100 \%)$ & $20(100 \%)$ \\
\hline
\end{tabular}

Table 2. Frequency of graft induced complications in 1-year follow-up after surgery

\begin{tabular}{|l|l|l|l|}
\hline Treatment Group & Infection & Bleeding & Still syndrome \\
\hline Group 1 (Aspirin) & $5.6 \%$ & 0 & 0 \\
\hline Group 2 (Aspirin + Dipyridamole) & 0 & $10 \%$ & 0 \\
\hline Group 3 (Placebo) & $5 \%$ & 0 & $5 \%$ \\
\hline p-value & 0.460 & 0.331 & 0.707 \\
\hline
\end{tabular}

\section{Discussion}

The primary cause of vascular access failure is venous stenosis at graft-vein anastomosis which leads to thrombosis. It has been well characterized that the aggressive neointimal hyperplasia is the main cause of venous stenosis in arteriovenous grafts (9-11). Currently, procedural intervention such as angioplasty is the principal approach to maintaining the patency of synthetic grafts after the development of venous stenosis or thrombosis (12). To date, no effective drug therapy has been reported to prevent neointimal hyperplasia because of the lack of understanding of the cellular and molecular mechanisms that lead to development of neointimal hyperplasia in hemodialysis patients (6). Several previous randomized trials of antithrombotic therapies have failed to demonstrate a significant improvement in the patency of arteriovenous grafts in patients undergoing hemodialysis $(13,14)$. The results of our trial failed to show a benefit of the drug, as compared with placebo, for the prevention of thrombosis. There were no statistical differences in grafts primary patency time when Aspirin or Aspirin with Dipyridamole was prescribed. Also, frequency of bleeding or other serious adverse events were not increased with the activation of our treatment. Our findings are not in agreement with the results of similar studies, which show that dipyridamole is beneficial in patients with new expanded polytetrafluoroethylene (ePTFE) grafts, but similar studies also released a similar result for the use of aspirin alone that did not reduce the likelihood of thrombosis in ePTFE grafts. Also, neither dipyridamole nor aspirin had any significant effect on patients with prior graft thrombosis (15). But the results of a recent study showed that dipyridamole treatment with aspirin in reducing the risk of stenosis and improving the primary patency of the graft, has significant effects (1). Yevzlin evaluated the relationship between anticoagulant or antiplatelet medication and vascular access patency including PTFE grafts in a group of hemodialysis patients. His cohort research findings showed that the antiplatelet agents which include ticlopidine, dipyridamole, or aspirin had a significant negative association with access patency (16). Also, the results of other valuable studies that investigate the prescription of aspirin alone or in combination with another antiplatelet drug are in favor of aspirin to increase the graft's patency $(14,17)$. Our hypothesis in this study was that dipyridamole, with direct effect on vascular smooth muscle, prevents the development of venous stenosis that leads to graft thrombosis (8). However, aspirin works primarily as an antiplatelet agent and the cumulative effect of these drugs may be more effective in the prevention of newly grafts dysfunction. Our results show that this effect seems to be dose dependent because the use of aspirin with or without dipyridamole at their baseline dose $(80 \mathrm{mg}$ and $75 \mathrm{mg}$ per day respectively) could not reduce the loss of primary unassisted graft patency versus placebo. Briefly, the recent studies show that high-dose aspirin prescription in hemodialysis patients probably improves the patency time of the grafts $(1,18)$ and the chance of some related complication, especially bleeding events, increases, which raises concerns about the use of these drugs (antiplatelet) in this group of patients (19). The benefits and disadvantages of prescribing antiplatelet drugs in dialysis patients have not yet been identified (19). In several studies, aspirin with low dose (30 mg and $81 \mathrm{mg}$ per 
day) was used as the sole antiplatelet agent in hemodialysis patients, some of them reported an increased risk of bleeding $(20,21)$ and some of them reported that there was no increased risk in bleeding as compared with placebo $(18,22,23)$.

\section{Conclusions}

Our results demonstrated that the prescription of low dose aspirin (80 mg per day) with or without dipyridamole (75 mg per day) did not increase the bleeding events. We conclude, it is difficult to identify any beneficial effect of low dose aspirin with or without dipyridamole on graft access patency in hemodialysis patients, but if it is necessary to prescribe an antiplatelet for specific indications, aspirin can be prescribed with low dose without likely risk of bleeding, related to the patient's hemodialysis. However, we suggest future projects to investigate the higher dose of anti-platelet drugs such as aspirin on patency of arteriovenous grafts in ESRD patients.

\section{Acknowledgments:}

With special gratitude to the Research Department of Mashhad University of Medical Sciences that scientifically and financially supported this study as a vascular surgery thesis with approval number 900813.

\section{Conflict of Interest:}

There is no conflict of interest to be declared.

\section{Authors' contributions:}

All authors contributed to this project and article equally. All authors read and approved the final manuscript.

\section{References:}

1) Dixon BS, Beck GJ, Vazquez MA, Greenberg A, Delmez JA, Allon M, et al. Effect of dipyridamole plus aspirin on hemodialysis graft patency. The New England journal of medicine. 2009; 360(21): 2191-201. doi: 10.1056/NEJMoa0805840. PMID: 19458364, PMCID: PMC3929400.

2) Tordoir J, Canaud B, Haage P, Konner K, Basci A, Fouque D, et al. EBPG on Vascular Access. Nephrology, dialysis, transplantation: official publication of the European Dialysis and Transplant Association - European Renal Association. 2007; 22 Suppl 2: ii88-117. doi: 10.1093/ndt/gfm021. PMID: 17507428.

3) Bethesda M. U.S. Renal Data System 2006 Annual data report: atlas of end-stage renal disease in the United States. National Institutes of Health, National Institute of Diabetes and Digestive and Kidney Diseases. 2006.

4) Roy-Chaudhury P, Sukhatme VP, Cheung AK. Hemodialysis vascular access dysfunction: a cellular and molecular viewpoint. Journal of the American Society of Nephrology: JASN. 2006; 17(4): 1112-27. doi: 10.1681/ASN.2005050615. PMID: 16565259.

5) Gibson KD, Gillen DL, Caps MT, Kohler TR, Sherrard DJ, Stehman-Breen CO. Vascular access survival and incidence of revisions: a comparison of prosthetic grafts, simple autogenous fistulas, and venous transposition fistulas from the United States Renal Data System Dialysis Morbidity and Mortality Study. Journal of vascular surgery. 2001; 34(4): 694-700. doi: 10.1067/mva.2001.117890. PMID: 11668326.

6) Lee T, Roy-Chaudhury P. Advances and new frontiers in the pathophysiology of venous neointimal hyperplasia and dialysis access stenosis. Advances in chronic kidney disease. 2009; 16(5): 329-38. doi: 10.1053/j.ackd.2009.06.009. PMID: 19695501, PMCID: PMC2764321.

7) Tanner NC, Da Silva A. Medical adjuvant treatment to increase patency of arteriovenous fistulae and grafts. Cochrane Database Syst Rev. 2015; 7: CD002786. doi: 10.1002/14651858.CD002786.pub3. PMID: 26184395.

8) Dixon BS, Beck GJ, Dember LM, Depner TA, Gassman JJ, Greene T, et al. Design of the Dialysis Access Consortium (DAC) Aggrenox Prevention Of Access Stenosis Trial. Clinical trials. 2005; 2(5): 400-12. doi: 10.1191/1740774505cn110oa. PMID: 16317809.

9) Roy-Chaudhury P, Arend L, Zhang J, Krishnamoorthy M, Wang Y, Banerjee R, et al. Neointimal hyperplasia in early arteriovenous fistula failure. American journal of kidney diseases. 2007; 50(5): 782-90. doi: 10.1053/j.ajkd.2007.07.019. PMID: 17954291.

10) Roy-Chaudhury P, Kelly BS, Miller MA, Reaves A, Armstrong J, Nanayakkara N, et al. Venous neointimal hyperplasia in polytetrafluoroethylene dialysis grafts. Kidney international. 2001; 59(6): 2325-34. doi: 10.1046/j.1523-1755.2001.00750.x. PMID: 11380837. 
11) Wang Y, Krishnamoorthy M, Banerjee R, Zhang J, Rudich S, Holland C, et al. Venous stenosis in a pig arteriovenous fistula model--anatomy, mechanisms and cellular phenotypes. Nephrol Dial Transplant. 2008; 23(2): 525-33. doi: 10.1093/ndt/gfm547. PMID: 18037619.

12) Allon M. Current management of vascular access. Clin J Am Soc Nephrol. 2007; 2(4): 786-800. doi: 10.2215/CJN.00860207. PMID: 17699495.

13) Crowther MA, Clase CM, Margetts PJ, Julian J, Lambert K, Sneath D, et al. Low-intensity warfarin is ineffective for the prevention of PTFE graft failure in patients on hemodialysis: a randomized controlled trial. J Am Soc Nephrol. 2002; 13(9): 2331-7. doi: 10.1097/01.ASN.0000027356.16598.99. PMID: 12191977.

14) Kaufman JS, O'Connor TZ, Zhang JH, Cronin RE, Fiore LD, Ganz MB, et al. Randomized controlled trial of clopidogrel plus aspirin to prevent hemodialysis access graft thrombosis. J Am Soc Nephrol. 2003; 14(9): 2313-21. doi: 10.1097/01.ASN.0000081661.10246.33. PMID: 12937308.

15) Sreedhara R, Himmelfarb J, Lazarus JM, Hakim RM. Anti-platelet therapy in graft thrombosis: results of a prospective, randomized, double-blind study. Kidney international. 1994; 45(5): 1477-83. doi: 10.1038/ki.1994.192. PMID: 8072261.

16) Yevzlin AS, Conley EL, Sanchez RJ, Young HN, Becker BN. Vascular access outcomes and medication use: a USRDS study. Semin dial. 2006; 19(6): 535-9. doi: 10.1111/j.1525-139X.2006.00218.x. PMID: 17150056.

17) Saran R, Dykstra DM, Wolfe RA, Gillespie B, Held PJ, Young EW, et al. Association between vascular access failure and the use of specific drugs: the Dialysis Outcomes and Practice Patterns Study (DOPPS). American journal of kidney diseases. 2002; 40(6): 1255-63. doi: 10.1053/ajkd.2002.36895. PMID: 12460045.

18) Harter HR, Burch JW, Majerus PW, Stanford N, Delmez JA, Anderson CB, et al. Prevention of thrombosis in patients on hemodialysis by low-dose aspirin. The New England journal of medicine. 1979; 301(11): 577-9. doi: 10.1056/NEJM197909133011103. PMID: 112475.

19) Hiremath S, Holden RM, Fergusson D, Zimmerman DL. Antiplatelet medications in hemodialysis patients: a systematic review of bleeding rates. Clin J Am Soc Nephrol. 2009; 4(8): 1347-55. doi: 10.2215/CJN.00810209. PMID: 19578002, PMCID: PMC2723969.

20) Holden RM, Harman GJ, Wang M, Holland D, Day AG. Major bleeding in hemodialysis patients. Clin J Am Soc Nephrol. 2008; 3(1): 105-10. doi: 10.2215/CJN.01810407. PMID: 18003768, PMCID: PMC2390984.

21) Obialo CI, Conner AC, Lebon LF. Maintaining patency of tunneled hemodialysis catheters--efficacy of aspirin compared to warfarin. Scandinavian journal of urology and nephrology. 2003; 37(2): 172-6. doi: 10.1080/00365590310008938. PMID: 12745728.

22) Ethier J, Bragg-Gresham JL, Piera L, Akizawa T, Asano Y, Mason N, et al. Aspirin prescription and outcomes in hemodialysis patients: the Dialysis Outcomes and Practice Patterns Study (DOPPS). American journal of kidney diseases. 2007; 50(4): 602-11. doi: 10.1053/j.ajkd.2007.07.007. PMID: 17900460.

23) Wasse H, Gillen DL, Ball AM, Kestenbaum BR, Seliger SL, Sherrard D, et al. Risk factors for upper gastrointestinal bleeding among end-stage renal disease patients. Kidney international. 2003; 64(4): 145561. doi: 10.1046/j.1523-1755.2003.00225.x. PMID: 12969166. 